\title{
IMPLEMENTASI SISTEM KELISTRIKAN HIBRIDA UNTUK KANDANG AYAM TERPADU DI NAGARI SALAREH AIA
}

\section{IMPLEMENTATION OF HYBRID ELECTRICAL SYSTEM FOR INTEGRATED CHICKEN CAGE IN NAGARI SALAREH AIA}

\author{
Muldi Yuhendri $^{1{ }^{*}}$, Mukhlidi Muskhir ${ }^{2)}$, Risfendra $^{3)}$, Hambali $^{4)}$ \\ ${ }^{1)}$ Fakultas Teknik, Universitas Negeri Padang, email: muldiy@,ft.unp.ac.id \\ ${ }^{2)}$ Fakultas Teknik, Universitas Negeri Padang, email: muskhir@gmail.com \\ ${ }^{3)}$ Fakultas Teknik, Universitas Negeri Padang, email: risfendra@,ft.unp.ac.id \\ ${ }^{4)}$ Fakultas Teknik, Universitas Negeri Padang, email: hambali.rsyd@gmail.com
}

\begin{abstract}
ABSTRAK
Sistem kelistrikan sangat berperan penting pada peternakan ayam, terutama untuk pembibitan anak ayam yang menggunakan mesin tetas telur dan untuk pemanasan dan penerangan pada kandang day old chicken (DOC). Dalam program pengabdian masyarakat ini diusulkan sistem kelistrikan hibrida untuk kandang terpadu di sentra peternakan ayam kampung di Nagari Salareh Aia. Kandang terpadu ini terdiri dari kandang DOC, kandang indukan, kandang pembesaran dan tempat mesin tetas telur untuk pembibitan DOC. Sistem kelistrikan hibrida yang diusulkan ini terdiri dari pembangkit listrik tenaga surya (PLTS) $400 \mathrm{WP}$, baterai 200 Ah dan sumber listrik dari PLN. Sistem kelistrikan hibrida ini dirancang untuk menjaga kontiniutas penyediaan daya listrik pada kandang terpadu, karena ada beberapa peralatan yang tidak boleh terputus penyediaan listriknya, seperti untuk mesin tetas telur pada waktu penetasan, pemanasan dan penerangan untuk kandang DOC dan sebagainya. Hasil eksperimen di lokasi pengabdian masyarakat menunjukan bahwa sistem kelistrikan hibrida yang diusulkan telah sukses menjaga kontiniutas penyediaan daya listrik untuk kandang ayam terpadu, sehingga mesin tetas telur dapat bekerja dengan baik selama penetasan. Begitu juga temperatur kandang DOC dapat dipertahankan konstan sesuai dengan standar temperatur kandang DOC.
\end{abstract}

Kata kunci : Kelistrikan Hibrida, Kandang Ayam, PLTS, Baterai, Mesin Tetas

\section{ABSTRACT}

The electrical system plays an important role in chicken farming, especially for breeding chicks that use egg incubators and for heating and lighting in the cages of the day old chicken (DOC). In this community service program, a hybrid electricity system for integrated cages at the center of a chicken farm in Nagari Salareh Aia is proposed. This integrated cage consists of a DOC cage, breeding cage, rearing cage and an egg hatching machine for DOC breeding. The proposed hybrid electricity system consists of a $400 \mathrm{WP}$ solar power plant, 200 Ah battery and a power source from PLN. This hybrid electrical system is designed to maintain the continuity of electricity supply in integrated cages, because there are some equipment that should not be interrupted, such as for hatching machines during hatching, heating and lighting for DOC cages and so on. The results of experiments at community service locations show that the proposed hybrid electrical system has been successful in maintaining continuity of electricity supply for integrated chicken coops, so that the egg hatching machine can work well during hatching. Likewise, DOC cage temperature can be kept constant according to DOC cage temperature standards.

Keywords: Hybrid Electrical System, Chicken Cage, PLTS, Battery, Egg Incubator

\section{PENDAHULUAN}

Salareh Aia adalah salah satu Nagari atau desa yang ada di kecamatan Palembayan Kabupaten Agam dengan jumlah penduduk adalah peternakan ayam kampung. Ayam sebanyak 12.439 orang [1]. Masyarakat Nagari ini umumnya hidup bertani dan beternak. Salah satu peternakan yang banyak dikembangkan 
kampung ini potensial untuk dikembangkan, bekerja dalam jangka waktu tertentu, seperti karena memiliki daya tahan tubuh yang baik, mesin tetas telur, pemanas untuk kandang DOC karkasnya lebih mahal serta lebih disukai oleh dan sebagainya [5].

konsumen [2].

Berdasarkan observasi yang dilakukan pada bulan Maret 2018, ditemukan bahwa sistem peternakan ayam kampung yang dilakukan masyarakat Salareh Aia masih bersifat ekstensif tradisional, yaitu dengan cara melepaskan ayam mencari ransum sendiri [2]. kelemahan sistem ini adalah laju reproduksi dan pertumbuhan ayam menjadi lambat [3]. Peningkatan reproduksi dan pertumbuhan ayam kampung dapat dilakukan dengan menerapkan pemeliharaan ayam secara intensif [4]. Pemeliharaan ayam secara intensif ini membutuhkan kandang yang memadai, yang mencakup kandang DOC, kandang pembesaran dan kandang indukan untuk reproduksi.

Untuk meningkatkan laju pertumbuhan dan reproduksi ayam kampung di Nagari Salareh Aia, maka melalui program pengabdian masyarakat pada tahun 2018 telah dibuat kandang ayam terpadu untuk pemeliharaan ayam kampung secara intensif, yang terdiri dari kandang DOC, kandang pembesaran, kandang indukan dan mesin tetas telur untuk penetasan.

Salah satu komponen penunjang yang sangat penting untuk kandang terpadu ini adalah energi listrik untuk berbagai kebutuhan, seperti untuk mesin tetas telur, pemanas dan penerangan untuk kandang DOC dan sebagainya. Penyediaan energi listrik untuk kandang ayam terpadu ini harus dapat dijaga kontiniutasnya, karena ada beberapa peralatan yang tidak boleh berhenti
Kontiniutas penyediaan energi listrik sangat tergantung pada kehandalan jaringan listrik PLN di lokasi tersebut. Berdasarkan observasi lapangan yang dilakukan pada tahun 2018 dapat disimpulkan bahwa kehandalan jaringan listrik di Nagari Salareh Aia masih rendah, karena sering mati, sehingga kurang memadai untuk menjaga kontiniutas daya listrik pada kandang ayam terpadu. Untuk mengatasi masalah ini, maka diusulkan sistem kelistrikan hibrida, yaitu sistem kelistrikan yang disuplai dari beberapa sumber [6]. Sistem kelistrikan hibrida ini banyak dirancang dengan memanfaatkan sumber energi terbarukan, seperti pembangkit listrik tenaga surya (PLTS) dan sebagainya [7]. Dalam program ini, dirancang sistem kelistrikan hibrida, yang terdiri dari jaringan PLN, PLTS dan baterai. Dengan konsep ini diiharapkan kontiniutas penyediaan daya listrik untuk kandang terpadu dapat dipertahankan.

\section{METODE PELAKSANAAN KEGIATAN}

Penerapan sistem kelistrikan hibrida untuk kandang ayam terpadu ini merupakan bagian dari program pengabdian masyarakat nagari binaan (desa mitra) yang dilakukan semenjak tahun 2018 sampai tahun 2020 di Nagari Salareh Aia Kecamatan Palembayan Kabupaten Agam, Sumatera Barat. Pengabdian ini melibatkan dua kelompok peternak, yaitu kelompok peternak Babussalam di Jorong Kampuang Tangah Barat dan kelompok peternak Jamaatul Muslimin di jorong Koto Alam. Implementasi sistem 
kelistrikan hibrida untuk kandang ayam terpadu ini merupakan lanjutan dari pengabdian tahun 2018, dimana pada tahun 2018 telah dilakukan pembuatan kandang ayam terpadu untuk pemeliharaan ayam kampung secara intensif.

Program pengabdian ini dilakukan dalam beberapa tahapan, yakni tahap observasi untuk melihat masalah yang ada pada mitra, tahap perancangan sistem kelistrikan hibrida, tahap pemasangan sistem kelistrikan hibrida di lokasi kandang terpadu dan tahap pengujian di lokasi.

Sistem kelistrikan hibrida yang dirancang untuk kandang ayam terpadu ini terdiri dari panel surya $400 \mathrm{wp}$, solar charger, inverter satu fasa, baterai kering deep cycle 200 Ah, Autamatic Transfer Switch (ATS) dan jaringan PLN. Sistem kelistrikan hibrida ini akan melayani beban di kandang terpadu berupa mesin tetas 200 butir telur berdaya 60 watt, lampu pemanas kandang DOC sebesar 240 watt dan lampu penerangan pada seluruh kandang ayam terpadu sebesar 60 watt. Gambar 1 menunjukan skema sistem kelistrikan hibrida yang diterapkan pada kandang ayam terpadu.

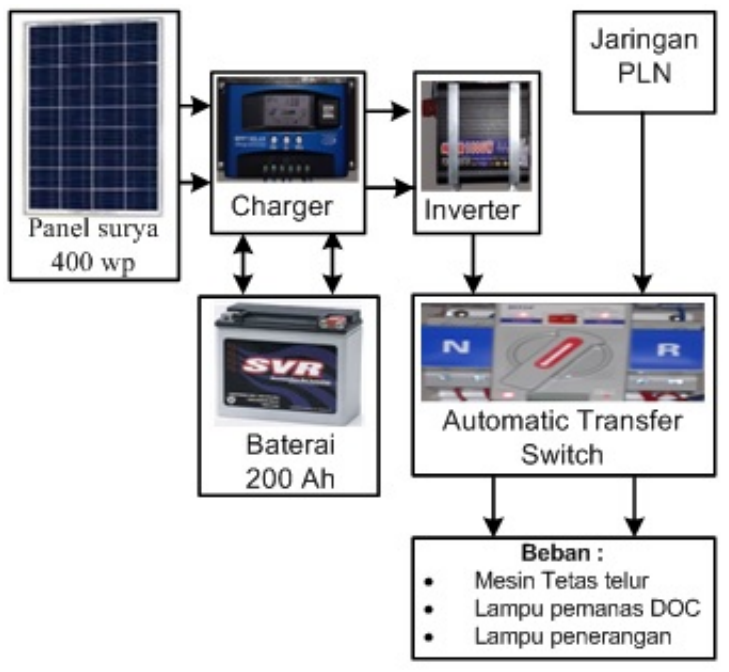

Gambar 1. Skema sistem kelistrikan hibrida

\section{HASIL DAN PEMBAHASAN}

Kegiatan pengabdian ini dilakukan dalam beberapa tahapan mulai dari bulan Juli sampai dengan Desember 2019. Setiap tahapan menargetkan hasil yang harus dicapai. Hasil yang diperoleh dalam setiap tahapan adalah sebagai berikut :

\section{Observasi}

Observasi dilakukan untuk mengetahui masalah yang dihadapi oleh kelompok peternak Babussalam dalam mengembang-kan peternakan ayam kampung secara intensif. Observasi dilakukan dengan cara diskusi dan melihat langsung ke lokasi peternakan ayam. Gambar 2 menunjukan peserta diskusi bersama pemerintah Nagari Salareh Aia dan kelompok peternak pada saat observasi.

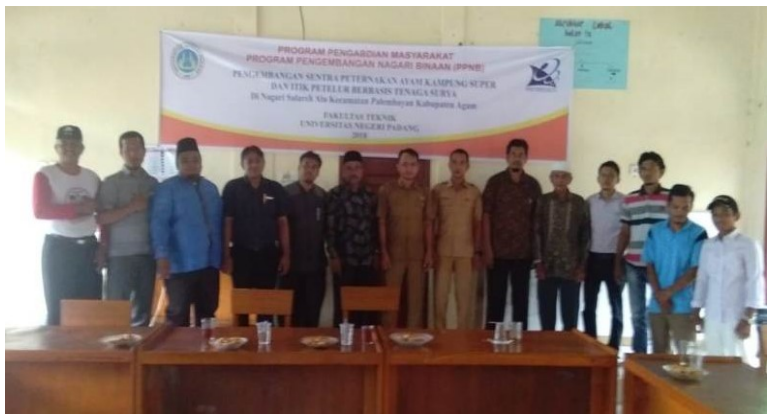

Gambar 2. Diskusi dengan Nagari mitra

Berdasarkan diskusi yang dilakukan, maka dapat disimpulkan bahwa untuk menyukseskan pelaksanaan pemeliharaan dan pembibitan ayam kampung secara intensif di sentra peternakan ayam Nagari Salareh Aia dibutuhkan sumber kelistrikan yang memadai untuk mendukung operasi mesin tetas telur dan pemanasan di kandang DOC. Hal ini disebabkan oleh rendahnya kehandalan jaringan listrik di daerah ini. 


\section{Merancang sistem kelistikan hibrida}

Sistem kelistrikan hibrida dirancang untuk mengatasi masalah kelistrikan di kandang ayam terpadu Nagari Salareh Aia. Gambar 3 menunjukan kandang yang akan dipasangkan sistem kelistrikan hibrida.
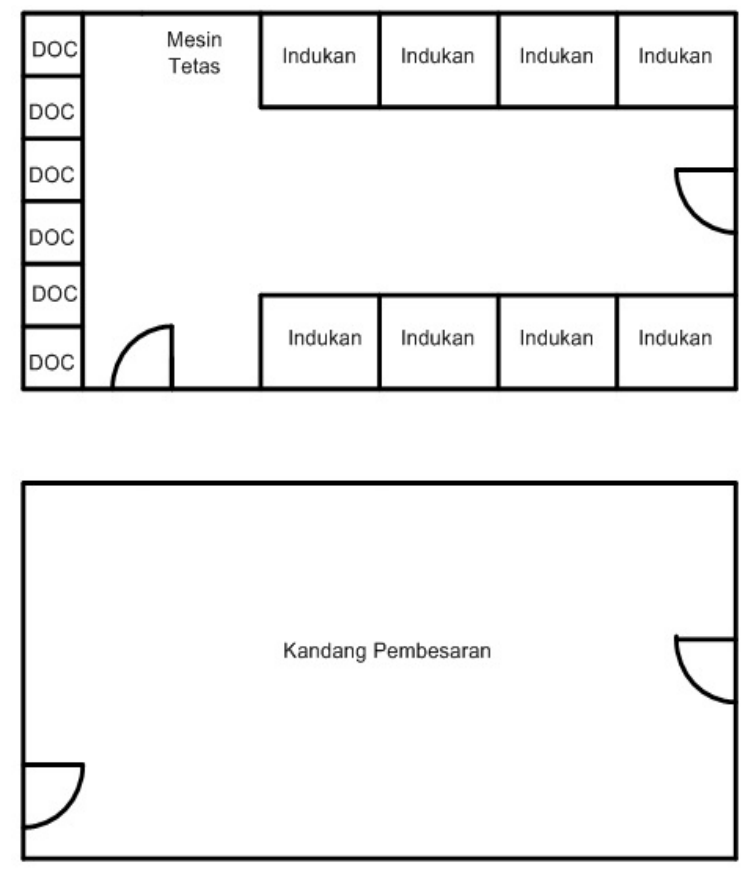

(a)

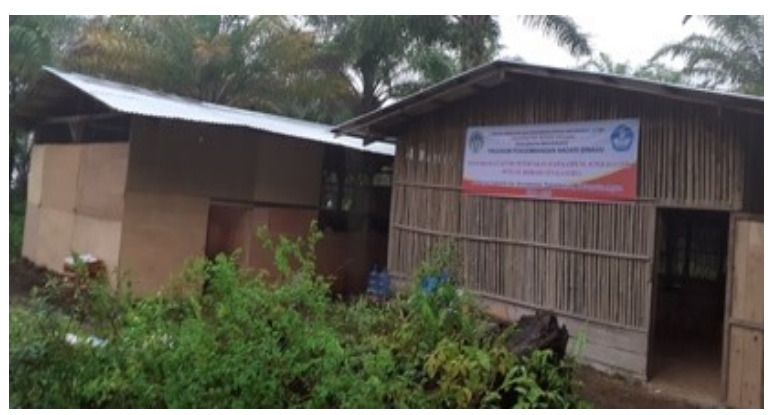

(b)

Gambar 3. Kandang ayam. (a) denah kandang, (b) bangunan kandang.

Kandang ayam terpadu ini terdiri dua buah kandang berukuran 12 x 6 meter. Kandang pertama berfungsi kandang pembe-saran dalam bentuk litter, seperti yang ditunjukan oleh Gambar 4. Kandang pembe-saran ini dapat menampung ayam sebanyak 500 ekor dengan

acuan standar kapasitas kandang pembesaran 5 -

7 ekor permeter persegi [8].

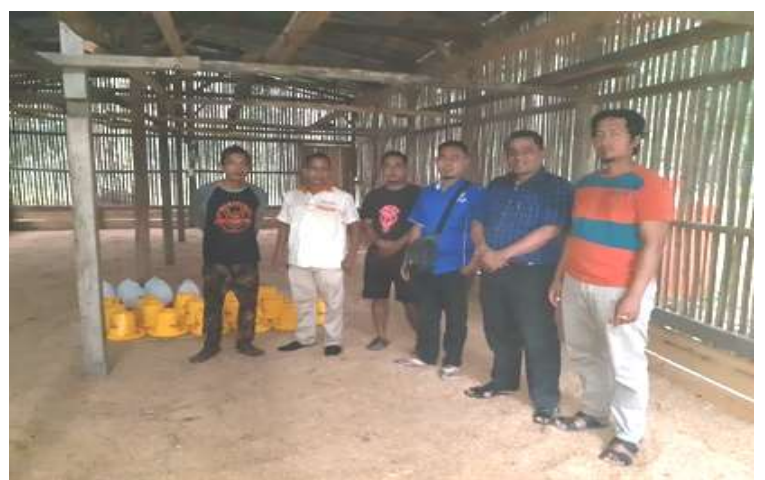

Gambar 4. Kandang pembesaran

Kandang kedua terdiri dari kandang indukan, kandang DOC dan tempat mesin tetas. Kandang indukan terdiri dari delapan kotak berukuran 1,5 × 2 x 1,8 meter dengan kapasitas 5 ekor permeter persegi [4]. Setiap kotak kotak kandang indukan ini akan diisi dengan lima ekor induk ayam, sehingga total indukannya adalah 40 ekor.

Kandang DOC dibuat dalam bentuk box dua tingkat sebanyak dua belas box dengan ukuran 1 x 1 x 0,5 meter masing-masingnya. Kapasitas kandang DOC adalah 40 ekor anak ayam permeter persegi [4]. Berdasarkan standar ini, maka kandang DOC yang ada di kandang ayam terpadu Nagari Salareh Aia dapat menampung sekitar 500 ekor anak ayam.

Rancangan sistem kelistrikan kandang ayam ini didasarkan pada kebutuhan yang harus dipenuhi agar kandang ayam dapat beroperasi se-suai dengan standar. Beberapa acuan yang digunakan dalam merancang sistem kelistrikan kandang ini adalah standar operasi mesin tetas telur, standar suhu kandang DOC dan kelayakan penerangan pada kedua kandang utama. Operasi mesin tetas telur harus dapat mempertahan suhu 
telur pada suhu $38^{\circ}-39^{\circ} \mathrm{C}$ untuk penetasan, energi untuk setiap kandang dengan daya menjaga kelembaban udara agar cangkang telur totalnya adalah 60 watt. Berdasarkan kebutuhan tidak keras dan melakukan pemutaran telur ini, maka daya listrik total yang diperlukan oleh secara berkala untuk mencegah embrio telur kandang adalah 360 watt.

melekat pada cangkang [9]. Untuk mencapai tujuan ini, maka digunakan mesin tetas otomatis 200 butir telur. Mesin tetas ini menggunakan delapan buah lampu pijar 5 watt sebagai pemanas inkubator yang dilengkapi dengan thermostat untuk mengatur suhu pad arak telur. Selain itu, mesin tetas ini juga sudah dilengkapi dengan motor penggerak rak yang dapat menggerakan telur secara otomatis setiap empat jam. Mesin tetas ini akan menyerap daya sebesar 60 watt. Gambar 5 menunjukan mesin tetas telur otomatis yang dipasang pada kandang ayam terpadu Nagari Salareh Aia.

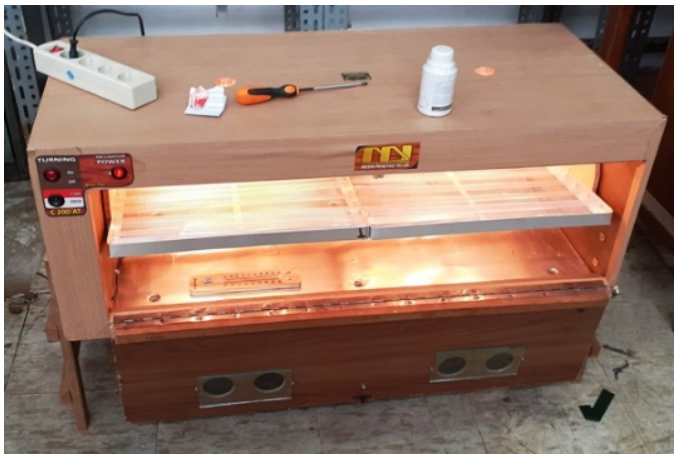

Gambar 5. Mesin tetas telur

Sistem pemanasan kandang DOC dengan lampu pijar harus dapat memper-tahankan suhu kandang sekitar $35^{\circ} \mathrm{C}$ [2]. Untuk menjaga suhu kandang ini, maka setiap box kandang dipasang lampu pijar sebanyak 2 buah, sehingga daya listrik total pada kandang DOC adalah 240 watt. Selain untuk kandang DOC dan mesin tetas, daya listrik juga digunakan untuk kebutuhan penerangan pada kedua kandang. Untuk penerangan ini, dipasang dua titik lampu hemat
Kebutuhan daya listrik kandang ini akan disuplai dengan sumber listrik hibrida, yang terdiri dari jaringan listrik 900 VA dan PLTS, yang terdiri dari panel surya dan baterai. Kapasitas panel surya yang harus dipasang ditentukan oleh lama waktu pengisian baterai, sedangkan kapasitas baterai ditentukan oleh jangka waktu penyuplaian daya dari baterai ke beban [10]. Dalam pengabdian ini, panel surya dirancang untuk menyuplai baterai selama delapan jam pada siang hari, sedangkan kapasitas baterai dirancang untuk menyuplai beban selama enam jam. Berdasarkan acuan ini dan daya yang dibutuhkan beban, maka PLTS dirancang dengan menggunakan empat buah panel surya $100 \mathrm{WP}$ dengan penyimpan energi berupa baterai kering deep cycle 200 Ah. Nilai panel surya ini didapatkan dengan acuan efisiensi panel surya sebesar $70 \%$.

\section{Memasang sistem kelistrikan hibrida}

Pemasangan sistem kelistrikan hibrida di lokasi kandang dilakukan oleh tim pengabdian yang terdiri dari dosen dan teknisi, yang dibantu oleh pengelola kandang. Gambar 6 menunjukan tim yang yang turun ke lapangan untuk memasang sistem kelistrikan hibrida di lokasi kandang. 


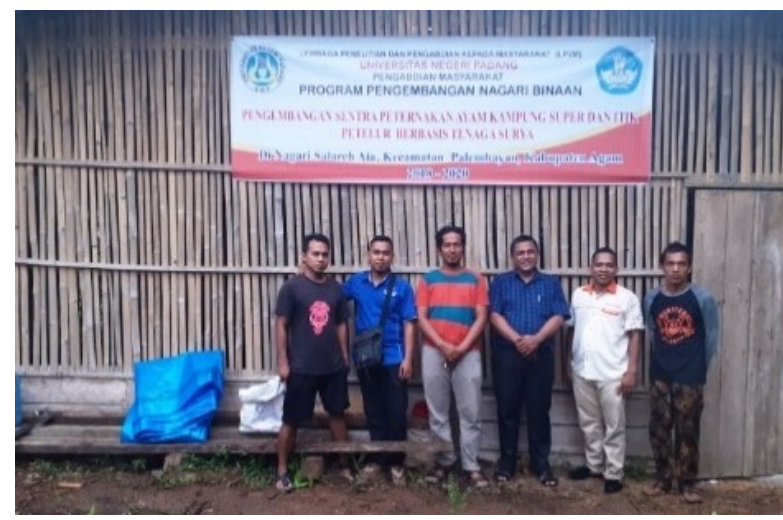

Gambar 6. Tim pengabdian di lokasi kandang terpadu

Pemasangan sistem kelistrikan hibrida di kandang terpadu dimulai dengan pemasangan instalasi penerangan untuk kedua kandang utama dan kandang DOC. Gambar 7 menunjukan proses pemasangan instalasi penerangan di kandang DOC.

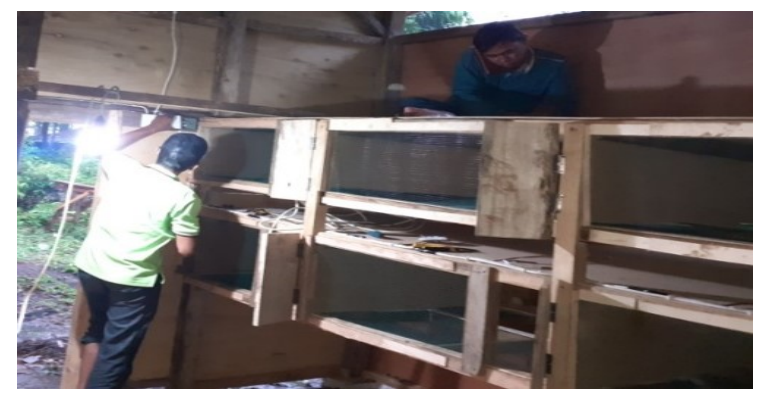

Gambar 7. Pemasangan instalasi penerangan di kandang DOC

Selanjutnya dilakukan pemasangan panel kontrol, mesin tetas telur, baterai dan instalasinya di tempat mesin tetas telur, seperti yang ditunjukan oleh Gambar 8. Panel kontrol berisikan solar charger, inverter dan ATS.

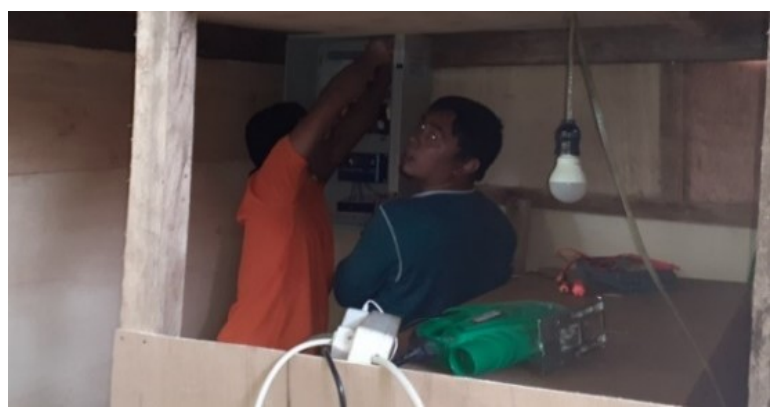

Gambar 8. Pemasangan mesin tetas dan panel kontrol
Setelah pemasangan panel kontrol selesai, selanjutnya dilakukan pemasangan panel surya di atas atap kandang, seperti yang ditunjukan oleh Gambar 9. Setelah semuanya selesai, selanjutnya ATS pada panel kontrol dihubungkan dengan jaringan listrik dari PLN.

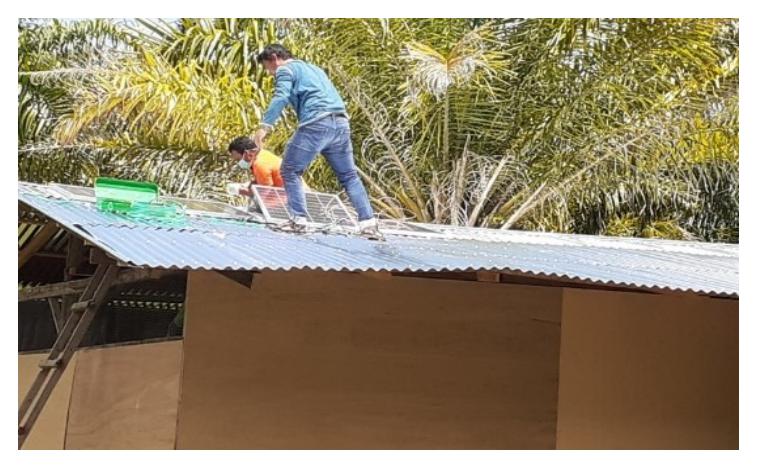

Gambar 9. Pemasangan panel surya

\section{Pengujian sistem kelistrikan hibrida}

Setelah pemasangan semua komponen selesai dilakukan, selanjutnya pada hari kedua dilakukan uji kelayakan sistem kelistrikan hibrida di lokasi kandang terpadu. Pengujian dilakukan dalam beberapa tahap, yaitu pengujian parameter kelistrikan, pengujian mesin tetas dan pengujian penerangan pada kandang DOC.

Pengujian parameter kelistrik-an dilakukan untuk melihat nilai tegangan dan frekuensi yang dihasilkan oleh sistem kelistrikan hibrida ini. Parameter sistem kelistrikan hibrida ini dianggap layak jika tegangan dan frekuensi yang dihasilkan sudah sesuai dengan standar tegangan dan frekuensi yang dibutuhkan, yaitu sebesar 220 Volt 50 Hz. Pengujian parameter kelistrikan ini dilakukan pada terminal terminal yang terdapat pada panel kontrol dengan menggunakan osiloskop, seperti yang ditunjukan oleh Gambar 10 berikut. 


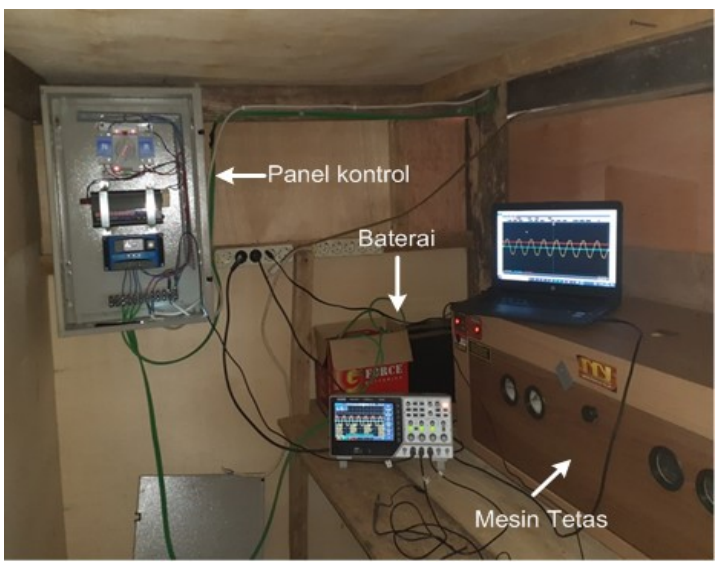

Gambar 10. Pengujian tegangan pada panel kontrol

Parameter tegangan yang diamati mencakup tegangan panel surya, baterai, output inverter dan tegangan jaringan listrik PLN. Gambar 11 menunjukan hasil pengu-kuran tegangan panel surya dan baterai yang dilakukan pada pukul 15.00 WIB.

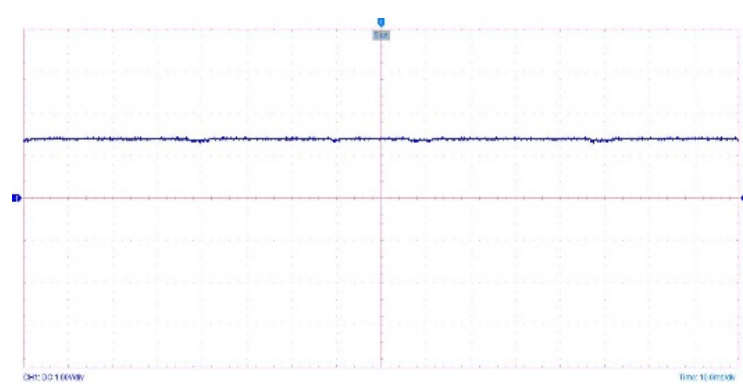

(a)

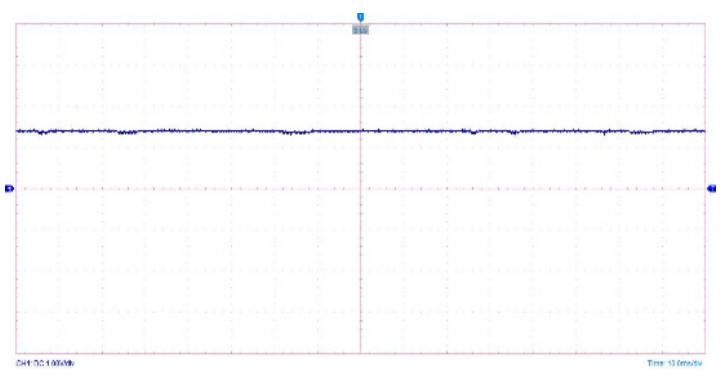

(b)

Gambar 11. Hasil pengukuran tegangan dc. a) Tegangan panel surya, b) tegangan baterai

Gambar 11(a) menunjukan bahwa tegangan panel surya pada terminal charger adalah 13,5 volt, sesuai dengan tegangan yang dibutuhkan untuk pengisian baterai. Hal ini menunjukan bahwa solar charger telah bekerja dengan baik mengendalikan tegangan output panel surya dari 21 volt menjadi 13,5 volt. Gambar 11(b) menunjukan bahwa tegangan baterai pada saat ini sebesar 11,8 Volt. Hal ini menunjukan baterai masih dalam kondisi penuh.

Selanjutnya dilakukan pengukuran tegangan ac dari output inverter dan jaringan PLN dengan hasil seperti yang ditunjukan oleh Gambar 12.

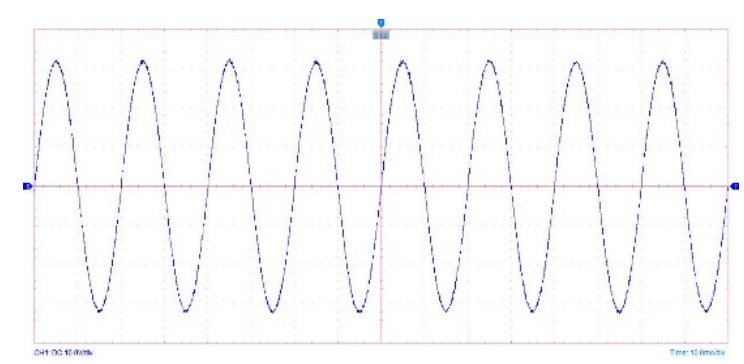

(a)

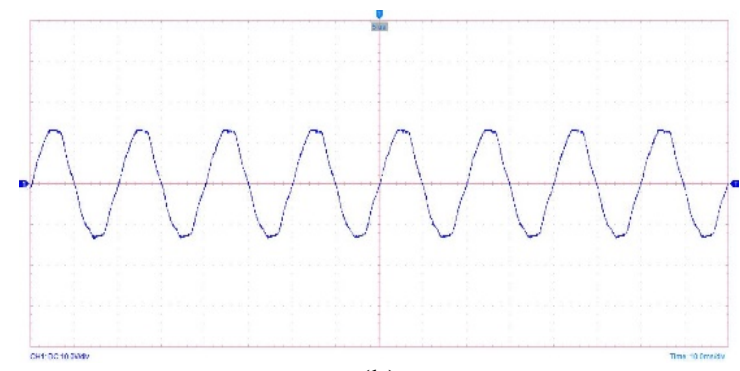

(b)

Gambar 12. Hasil pengukuran tegangan ac. a) Tegangan inverter dan $b$ ) tegangan jaringan PLN

Gambar 12(a) menunjukan bahwa inverter telah mampu menghasilkan tegang-an ac satu fasa dalam bentuk gelombang sinus murni dengan rms 220 volt dan frekuensi 49,9 Hz. Nilai ini sudah memenuhi standar kelistrikan satu fasa untuk melayani beban yang ada di kandang terpadu. Hasil yang sama juga didapat dari jaringan PLN, seperti yang ditunjukan oleh Gambar 12(b).

Semua hasil ini menunjukan bahwa parameter tegangan sistem kelistrikan hibrida 
untuk kandang ayam terpadu telah memenuhi otomatis. Gambar 14 menunjukan grafik suhu standar untuk melayani mesin tetas dan beban inkubator yang diukur dengan thermometer lainnya.

analog selama 30 menit.

Selanjutnya dilakukan pengujian kelis-trikan mesin tetas telur. Dalam pengujian ini, mesin tetas telur diisi dengan 100 butir telur ayam kampung. Gambar 13 menunjukan proses pengujian mesin tetas telur.

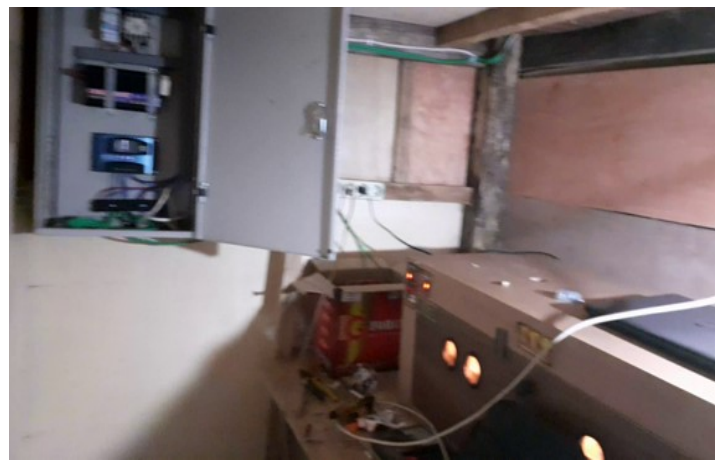

(a)

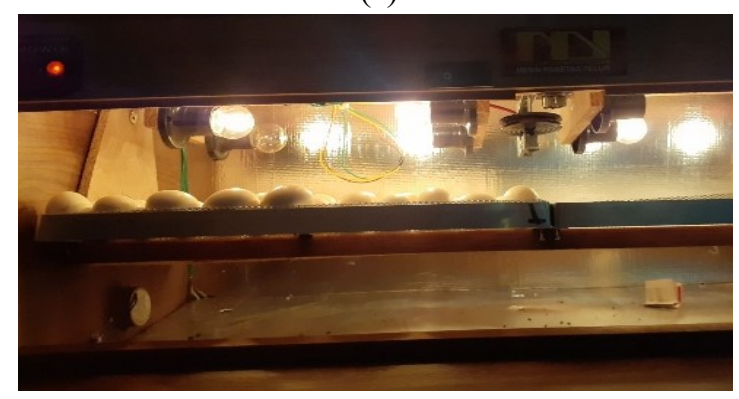

(b)

Gambar 13. Pengujian mesin tetas.

a) Tampak luar, b) tampak dalam

Gambar 13(a) menunjukan kondisi mesin tetas saat beroperasi, dimana lampu indikatornya menyala dan Gambar 13(b) menunjukan bagian dalam mesin tetas dengan lampu pijar yang sedang menyala untuk mengontrol suhu telur. Hasil pengamatan ini menunjukan sistem bahwa kelistrikan hibrida telah mampu menyuplai mesin tetas dengan baik, sehingga mesin tetas telur dapat beroperasi sesuai dengan yang diinginkan. Hal ini dapat dilihat dari indikator suhu pada inkubator dan gerakan rak telur yang

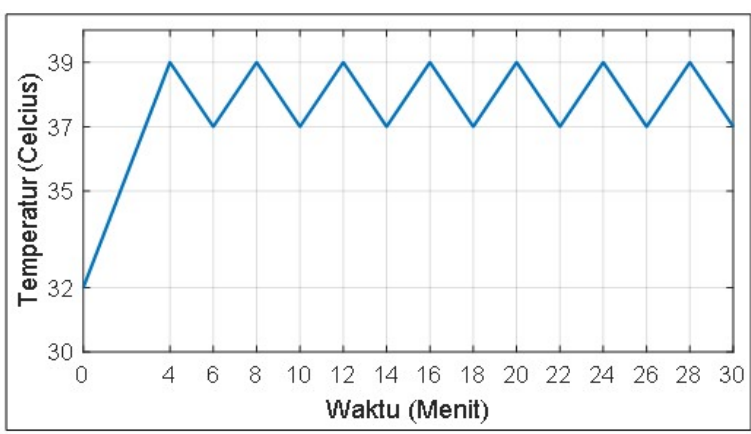

Gambar 14. Suhu inkubator mesin tetas telur

Gambar 14 menunjukan bahwa suhu inkubator telah sesuai dengan standar suhu penetasan telur ayam, yaitu $37^{\circ}-39^{\circ} \mathrm{C}$ [4]. Hal ini menunjukan bahwa sistem otomasi suhu yang yang menggunakan thermostad pada ruang inkubator telah bekerja dengan baik mengatur suhu pada ruang inkubator. Thermostad akan memutuskan aliran listrik ke lampu pijar ketika suhu mencapai $39^{\circ} \mathrm{C}$ dan akan menghubungkan kembali ketika suhu di bawah $37^{\circ} \mathrm{C}$. Berdasarkan pengamatan yang dilakukan, waktu hidup dan matinya lampu pijar ini sekitar 2 menit, seperti yang ditunjukan oleh Gambar 14 . Batas suhu pada ruang inkubator ini dapat diatur dengan mengatur tuas thermostad.

Sistem otomasi mesin tetas juga telah mampu menggerakan rak telur setiap 4 jam dengan jarak 25 derajat, seperti yang ditunjukan oleh Gambar 15. Semua hasil ini menunjukan bahwa system kelistrikan hibrida telah mampu menyuplai mesin tetas dengan baik, sehingga mesin tetas bekerja sesuai prosedur. 


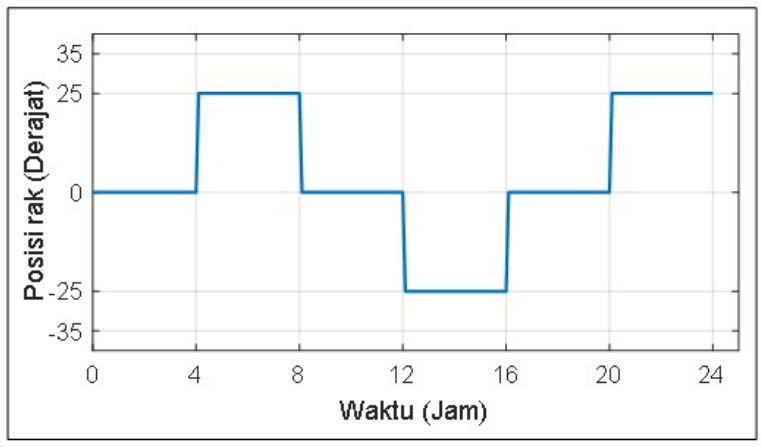

Gambar 15. Gerakan rak telur

Selanjutnya dilakukan pengujian lampu penerangan untuk pemanasan kandang DOC, dengan hasil seperti yang ditunjukan oleh Gambar 16.

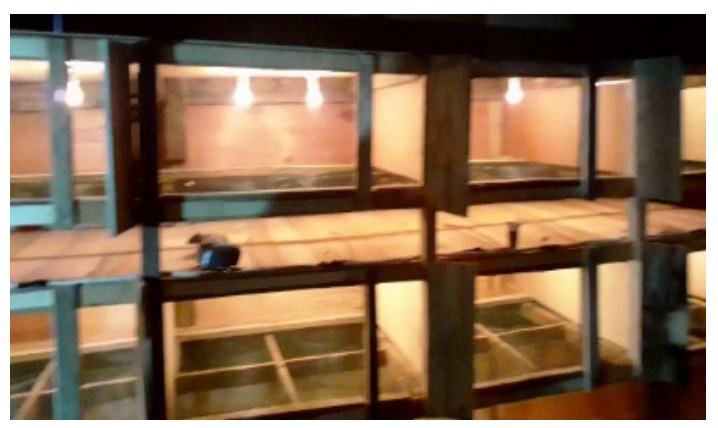

(a)

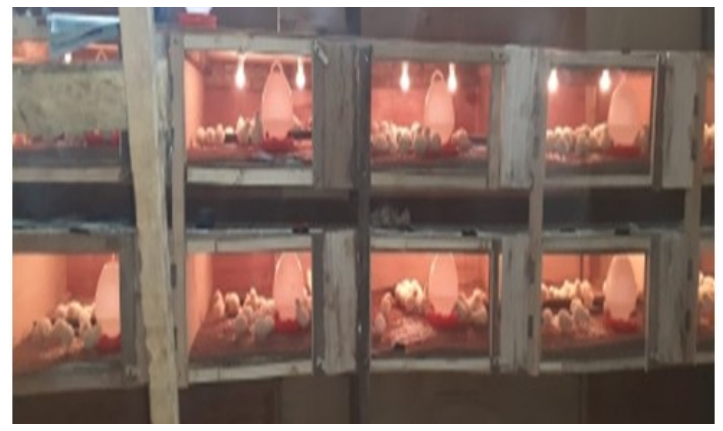

(b)

Gambar 16. Penerangan kandang DOC.

a) Tanpa DOC, b) kandang diisi DOC

Gambar 16 menunjukan bahwa semua lampu penerangan dalam kandang DOC telah menyala dengan baik. Penerangan ini telah mampu menghasilkan suhu kandang DOC sesuai dengan standar, yaitu sebesar $35^{\circ} \mathrm{C}$. Pengaturan suhu kandang DOC ini masih manual, dimana ketika suhu kandang sudah melebihi $35^{\circ} \mathrm{C}$, maka lampu dimatikan oleh pengelola. Begitu juga sebaliknya.

Selanjutnya dilakukan pengujian kemampuan baterai dalam menyuplai beban. Pengujian dilakukan pada malam hari ketika panel surya tidak menghasilkan daya. Hasil pengujian menunjukan bahwa baterai sebesar 200 Ah yang dipasang pada sistem kelistrikan hibrida ini hanya mampu melayani beban selama 5 jam 10 menit. Waktu ini berkurang sekitar 50 menit dari rancangan selama 6 jam. Hal ini mungkin disebabkan oleh adanya rugi-rugi daya yang harus disuplai oleh baterai. Secara keseluruhan sistem kelistrikan hibrida yang dirancang untuk kandang terpadu ini telah bekerja dengan baik sesuai perencanaan.

\section{KESIMPULAN}

Program pengabdian masyrakat ini mengusulkan sistem kelistrikan hibrida pada kandang ayam terpadu di Nagari Salareh Aia untuk mengatasi rendahnya kehandalan jaringan listrik di daerah tersebut. Sistem kelistrikan hibrida dirancang dengan menggabungkan jaringan listrik PLN dengan PLTS untuk menyuplai beban berupa mesin tetas dan lampu penerangan yang ada di kandang ayam tersebut. PLTS yang diusulkan terdiri dari empat buah panel surya 100 WP yang dilengkapi dengan baterai 200 Ah. Hasil pengujian di lapangan menunjukan bahwa sistem kelistrikan hibrida yang diusulkan telah bekerja dengan baik, sehingga semua beban listrik yang ada di kandang tersebut dapat bekerja sesuai standar. PLTS yang diusulkan telah mampu menyuplai beban selama 5 jam 10 menit, sehingga dapat 
menjaga kontiniutas penyaluran daya ke beban ketika jaringan listrik dari PLN mati.

\section{SARAN}

Program ini diharapkan dapat dikembangkan dengan anggaran yang lebih besar, sehingga memberi manfaat yang lebih besar bagi masyarakat

\section{UCAPAN TERIMAKASIH}

Terimakasih diucapkan kepada perang-kat dan masyarakat Nagari Salareh Aia yang telah terlibat dalam pengabdian ini serta LP2M Universitas Negeri Padang yang telah mendanai program ini melalui Hibah Program pengembangan Nagari Binaan.

\section{REFERENSI}

[1] Pemkab Agam. 2011. Profil Kecama-tan Palembayan

[2] Suryanto, D., Dinasari, I., Ali, U. 2018. Pengembangan pembibitan dan pengendalian produksi peternakan ayam kampung di pinggiran kota Malang, JIPEMAS: Jurnal Inovasi Hasil Pengabdian Masyarakat, 1(1):1-16

[3] Muryanto., Pramono, D. 2014. Sukses budi daya ayam kampung, Loka Aksara, Tangerang

[4] Hayanti, S. Y. 2014. Petunjuk teknis budidaya ayam kampung unggul, Balai Pengkajian Teknologi Pertanian, Jambi

[5] Adegbulugbe, T.A., Atere A.O., Fasan-mi O.G. 2013. Development of an Automatic Electric Egg Incubator, International Journal of Scientific \& Engineering Research, 4(9):914-918

[6] Hierro, J.G., Gonzalez, A. M., Barreiro, P., Robla, J. I. 2016. Evaluation of the solar contribution in a hybrid incubator of avian eggs, AgricEngInt, 18(4):133-146

[7] Mansaray, KG., Yansaneh, O. 2015.

Fabrication and performance evaluation of a solar powered chicken egg incubator, International Journal of Emerging Technology and Advanced Engineering, 5(6):31-36

[8] Iskandar, S. 2017. Petunjuk teknis produksi ayam lokal pedaging unggul, Pusat Penelitian dan Pengembangan Peternakan, Bogor

[9] Agidi, G., Liberty, J. T., Gunre, O. N., Owa, G. J. 2014. Design, construction and performance evaluation of an electric powered egg incubator, Inter-national Journal of Research in Engi-neering and Technology, 3(3):521-526

[10] Osanyinpeju, K. L., Aderinlewo, A. A., Adetunji, O. R., Ajisegiri, E. S. A. 2018. Performance evaluation of a solar powered poultry egg incubator, Interna-tional Research Journal of Advanced Engineering and Science, 3(2):255-264 